\title{
A functional assay for serum detection of antibodies against SARS-CoV-2 nucleoprotein
}

\author{
Anna Albecka ${ }^{1}$ (D) , Dean Clift ${ }^{1}$ (D), Marina Vaysburd ${ }^{1}$, Tyler Rhinesmith ${ }^{1}$, Sarah L Caddy ${ }^{1,2}$ (D), \\ David M Favara ${ }^{3,4,5}$, Helen E Baxendale ${ }^{6}$ \& Leo C James ${ }^{1, *}$ (D)
}

\begin{abstract}
The humoral immune response to SARS-CoV-2 results in antibodies against spike (S) and nucleoprotein (N). However, whilst there are widely available neutralization assays for $\mathrm{S}$ antibodies, there is no assay for $\mathrm{N}$-antibody activity. Here, we present a simple in vitro method called EDNA (electroporated-antibody-dependent neutralization assay) that provides a quantitative measure of $\mathrm{N}$-antibody activity in unpurified serum from SARS-CoV-2 convalescents. We show that $\mathrm{N}$ antibodies neutralize SARS-CoV-2 intracellularly and cell-autonomously but require the cytosolic Fc receptor TRIM21. Using EDNA, we show that low $\mathrm{N}$-antibody titres can be neutralizing, whilst some convalescents possess serum with high titres but weak activity. $\mathrm{N}$-antibody and $\mathrm{N}$-specific $\mathrm{T}$-cell activity correlates within individuals, suggesting $\mathrm{N}$ antibodies may protect against SARS-CoV-2 by promoting antigen presentation. This work highlights the potential benefits of $\mathrm{N}$-based vaccines and provides an in vitro assay to allow the antibodies they induce to be tested.
\end{abstract}

Keywords antibodies; neutralization; nucleoprotein; SARS-CoV-2; TRIM21 Subject Category Microbiology, Virology \& Host Pathogen Interaction DOI 10.15252/embj.2021108588 | Received 27 April 2021 | Revised 29 June 2021 | Accepted 2 July 2021 | Published online 29 July 2021

The EMBO Journal (2021) 40: e108588

\section{Introduction}

The immune response to SARS-CoV-2 results in a strong antibody response to both spike (S) and nucleoprotein (N) (Li et al, 2020). Antibodies against these two antigens have been widely used as diagnostics of past or present SARS-CoV-2 infection. Anti-S antibodies (or $\mathrm{S}$ antibodies) have been shown to neutralize SARS-CoV-2 and inhibit its replication, leading to their use as a rapid and effective antiviral treatment. Research into $\mathrm{S}$ antibodies has also played a vital role in the development of S-based vaccines, both by demonstrating that raising $\mathrm{S}$ antibodies is a worthwhile objective and by providing neutralization assays that allow correlates of protection to be established, a vital measure of vaccine efficacy. In contrast, despite the fact that anti- $\mathrm{N}$ antibodies (or $\mathrm{N}$ antibodies) are found in SARS-CoV-2 convalescents at levels that equal or exceed those of $\mathrm{S}$ antibodies (Rydyznski Moderbacher et al, 2020), there has been comparatively less investigation into their relevance beyond diagnostics. This is largely because unlike with anti-S antibodies, there is no assay that can measure if $\mathrm{N}$ antibodies block SARS-CoV-2 infection. However, it seems unlikely that a robust anti-N response plays no role in immunity to SARS-CoV-2. Studies in mice using murine hepatitis virus (MHV; a murine $\beta$-coronavirus with brain and liver tropism) have shown that passively transferred $\mathrm{N}$ antibodies are protective (Nakanaga et al, 1986; Lecomte et al, 1987). Indeed antibodies to internal antigens like $\mathrm{N}$ have been shown to prevent infection by arenaviruses (Richter \& Oxenius, 2013; Straub et al, 2013), ebolavirus (Wilson et al, 2000), human cytomegalovirus (HCMV; Bootz et al, 2017), human immunodeficiency virus (HIV; Excler et al, 2014; Mayr et al, 2017), influenza viruses (Sambhara et al, 2001; Carragher et al, 2008; LaMere et al, 2011) and vaccinia virus (Moss, 2011). Crucially however, because internal antigens are usually hidden inside the virion, antibodies against them do not bind infectious viral particles. Consequently, $\mathrm{N}$ antibodies and similar typically do not block infectious entry of viruses into cells in standard in vitro assays and are described as "nonneutralizing". The mechanisms behind the immune protection provided by non-neutralizing antibodies like $\mathrm{N}$ antibodies remain largely unknown.

Importantly, without functional data on SARS-CoV-2 $\mathrm{N}$ antibodies or an available assay to measure protective activity, there is less incentive to invest significant global effort into developing N-based vaccines. Meanwhile, although S-based vaccines are proving highly effective against SARS-CoV-2 transmission, there is growing evidence that emerging spike variants of SARS-CoV-2 are less susceptible to the immunity they induce (preprint: Garcia-Beltran et al, 2021; preprint: McCallum et al, 2021). The emergence of spike variants has also been seen in patients treated with convalescent plasma/monoclonals (Avanzato et al, 2020). The observed rapid

\footnotetext{
1 MRC Laboratory of Molecular Biology, Protein \& Nucleic Acid Division, Cambridge, UK

2 CITIID, Department of Medicine, University of Cambridge, Cambridge, UK

3 Department of Oncology, Addenbrooke's Hospital, Cambridge University Hospitals NHS Foundation Trust, Cambridge, UK

4 Department of Oncology, The Queen Elizabeth Hospital, The Queen Elizabeth Hospital King's Lynn NHS Foundation Trust, Kings Lynn, UK

5 Department of Oncology, University of Cambridge, Cambridge, UK

6 Royal Papworth NHS Trust, Cambridge, UK

*Corresponding author. Tel: +44 1223 267162; E-mail: Icj@mrc-Imb.cam.ac.uk
} 
mutation of SARS-CoV-2 spike underlies the widely held view that new vaccines may be required seasonally, unless the virus can be globally eradicated. One solution is to keep making new variant Svaccines, but another is to use a combined approach immunizing with a vaccine that contains both $\mathrm{S}$ and $\mathrm{N}$, making it much less likely for a resistant virus to emerge. All 10 currently authorized and approved SARS-CoV-2 vaccines are S-based. We therefore set out to develop an assay for $\mathrm{N}$-antibody activity, both to provide evidence for the inclusion of $\mathrm{N}$ as a candidate vaccine antigen and to allow N-based vaccines to be efficiently tested. The assay we developed, named EDNA (for electroporated-antibody-dependent neutralization assay), provides the only in vitro method that allows the antiviral activity of $\mathrm{N}$ antibodies in SARS-CoV-2 convalescent serum to be rapidly and quantitatively tested.

\section{Results}

\section{Antibodies mediate intracellular neutralization of MHV}

As MHV is a class 1 biosafety pathogen, and $\mathrm{N}$ antibodies are known to play a role in immunity to MHV in vivo (Nakanaga et al, 1986; Lecomte et al, 1987), we decided to use this as a model system to develop an assay that could be used to measure $\mathrm{N}$ antibody activity. First, we established a system to quantify MHV replication based on syncytia formation and cytopathic effect (CPE). Live phase-contrast microscopy revealed cell-cell fusion occurs 8$10 \mathrm{~h}$ after MHV-A59 infection and peaks at $30 \mathrm{~h}$, followed by lysis and cell death (Movie EV1, Appendix Fig S1A). Plotting either cell area quantified from live imaging or cell viability determined by total ATP levels at $48 \mathrm{~h}$ post-infection against virus dilution gave almost identical dose-response curves and TCID50 values (Appendix Fig S1B-D). Thus, live-cell imaging can be used to follow cytopathic MHV infection over time and accurately quantify virus titre. Using this approach, we tested the neutralization capacity of a polyclonal antiserum raised against disintegrated, purified MHVA59 virions (Rottier et al, 1981) that includes antibodies against both MHV-A59 S and N (Appendix Fig S1E). Antiserum was added to the cell media, or delivered directly into the cytosol by adapting our previously described Trim-Away technology (Clift et al, 2017). In Trim-Away, antibodies are electroporated into cells and form a complex with their protein target. This complex is recognized by the cytosolic Fc receptor and E3 ubiquitin ligase TRIM21 (James et al, 2007), which uses ubiquitination to recruit the proteasome and mediate complex degradation (Mallery et al, 2010; Kiss et al, 2021). Remarkably, the antiserum reduced MHV-A59 replication 10-fold more potently when delivered intracellularly than added extracellularly (Fig 1A-C). This suggests that there are antibodies present in the antiserum that can bind to viral proteins post-fusion in the cytosol and neutralize replication.

To test if anti-N antibodies are responsible for the block to replication, we electroporated L929 cells with serial dilutions of an anti-N monoclonal antibody (Leibowitz et al, 1987) or a control anti-GFP antibody and infected with MHV-A59. Strikingly, electroporation of the anti-N monoclonal antibody completely neutralized MHV-A59, whereas the control anti-GFP antibody had no effect (Fig 1D-F). Previously, we have shown that intracellular antibodydependent neutralization (ADIN), in which non-enveloped viruses pre-bound by antibody are neutralized after entry into the cytosol, is dependent on TRIM21 (Mallery et al, 2010). Upon binding to antibody-coated viruses, TRIM21 mediates rapid proteasomal- and VCP-dependent viral degradation (Hauler et al, 2012) and thereby blocks replication. To test whether this is also the case for electroporated anti-N antibodies and MHV-A59, we generated CRISPR TRIM21 knockout L929 cells (Appendix Fig S1F). TRIM21 knockout did not affect cell proliferation or cytopathic MHV-A59 infection in the absence of serum or antibody (Appendix Fig S1G). However, TRIM21 knockout cells could no longer neutralize MHV-A59 when electroporated with MHV antiserum or anti-N monoclonal antibody, suggesting that intracellular neutralization is completely TRIM21dependent (Fig $1 \mathrm{G}$ and $\mathrm{H}$ ). To further confirm the role of TRIM21 in intracellular neutralization, we co-electroporated anti-N antibody with excess recombinant protein A/G, which competes with TRIM21 for binding to IgG Fc (Keeble et al, 2008). The presence of protein A/G did not impact antibody electroporation efficiency or localization in the cytosol (Appendix Fig $\mathrm{S} 1 \mathrm{H}$ and I). However, coelectroporation of protein $\mathrm{A} / \mathrm{G}$ with anti- $\mathrm{N}$ antibody completely abolished intracellular neutralization of MHV-A59 in otherwise wildtype cells (Fig $1 \mathrm{H}$ ). These data suggest that anti-N antibodies neutralize MHV-A59 intracellularly by recruiting the cytosolic Fc receptor TRIM21. In both ADIN and Trim-Away, TRIM21 exerts its effects by targeting protein:antibody complexes for degradation. We therefore tested whether electroporated anti- $\mathrm{N}$ antibodies are causing degradation of MHV-A59 N protein. To do this, we allowed Nprotein expression for $4 \mathrm{~h}$ post-infection, blocked further N-protein expression by addition of cycloheximide (CHX) and then electroporated anti-N or anti-GFP antibodies or a no antibody control. Electroporation in the absence of antibody did not change N-protein levels (Appendix Fig S1J). Electroporation of anti-N but not antiGFP antibody led to a reduction in N-protein levels (Fig 1I). This is consistent with the block to MHV replication being caused by $\mathrm{N}$ protein degradation. Taken together, the data show that our electroporation-based method can be used to measure the activity of $\mathrm{N}$ antibodies in vitro. To distinguish this from the natural process of antibody-dependent intracellular neutralization (ADIN), we designated the approach "electroporated-antibody-dependent neutralization assay” (EDNA).

\section{EDNA can be used to measure intracellular antibody neutralization of SARS-CoV-2}

Next, we investigated whether EDNA could be used to investigate the $\mathrm{N}$-antibody response to SARS-CoV2. To do this, we used a clinical isolate of SARS-CoV-2/human/Liverpool/REMRQ0001/2020 and Vero cells modified to stably express SARS-CoV-2 entry factors ACE2 and TMPRSS2 (Papa et al, 2021). We added polyclonal rabbit anti-N antibodies or control rabbit IgG to Vero ACE2/TMPRSS2 with or without electroporation and after $24 \mathrm{~h}$ infected them with SARSCoV-2. To assess virus replication, we lysed the cells $24 \mathrm{~h}$ after infection and checked levels of genomic viral RNA by RT-qPCR. Electroporation of $\mathrm{N}$ antibodies reduced viral RNA by 3-logs (Fig 2A). Importantly, the same sera in the absence of electroporation had no impact on replication, indicating that $\mathrm{N}$ antibodies must be inside the cell to mediate neutralization. To confirm these results, we measured the effect of anti-N sera on the production of infectious particles after $24 \mathrm{~h}$ by plaque assay. In agreement with RT-qPCR, 


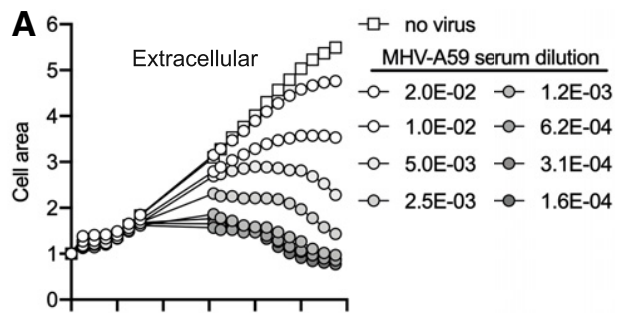

B

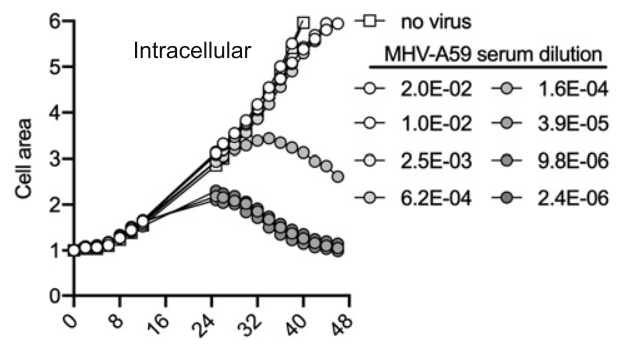

D

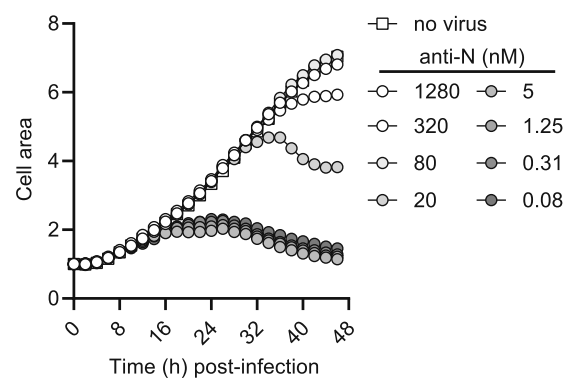

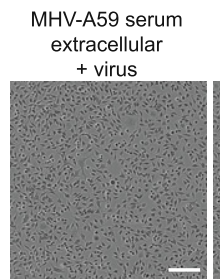

no serum

+ virus

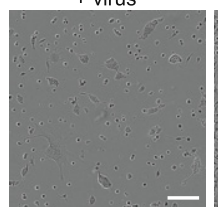

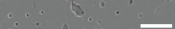

E

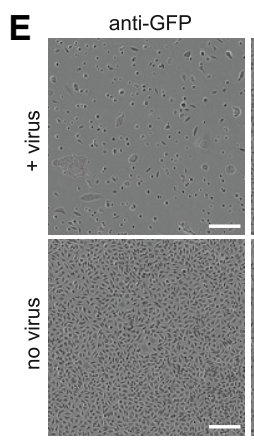

C

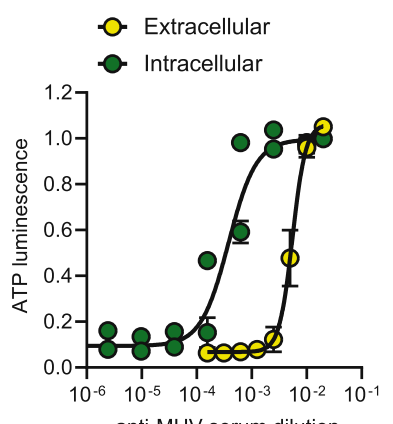

anti-MHV serum dilution
G

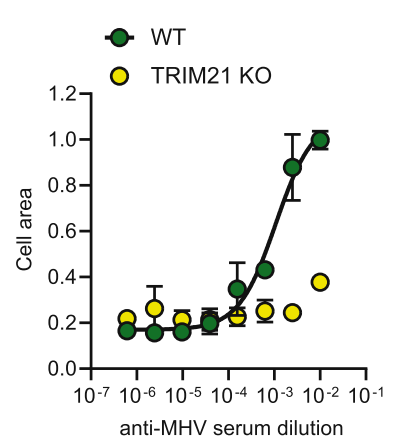

H

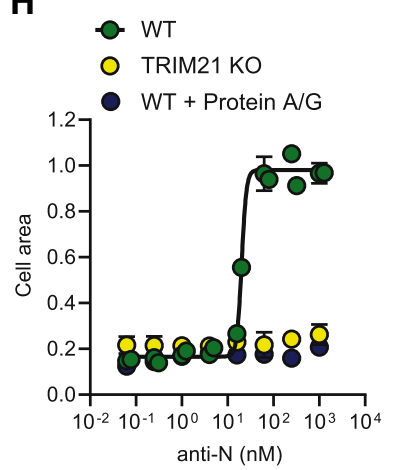

MHV-A59 serum intracellular

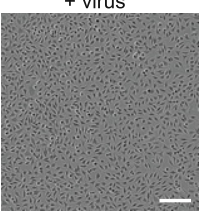

no serum

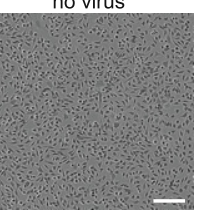

anti-N

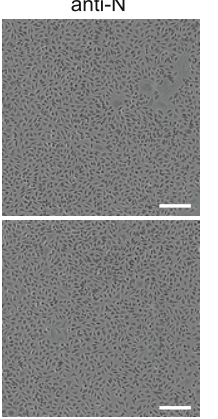

F

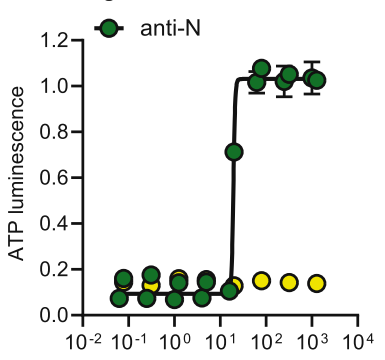

anti-N (nM)

I

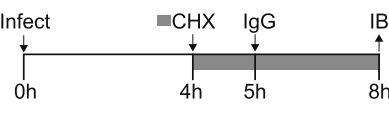

MHV-A59 + + -

anti-GFP + - -
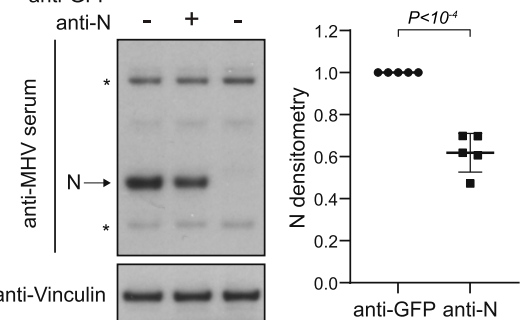

Figure 1. Electroporated-antibody-dependent neutralization assay (EDNA) for coronavirus.

A A titration of anti-MHV polyclonal serum was added either directly to media (extracellular) or electroporated into L929 cells (intracellular), and then, cells were infected with MHV-A59. The kinetics of cell growth was monitored by measuring total cell area.

B Phase-contrast images of cells at $48 \mathrm{~h}$ post-infection. Scale bar $=200 \mu \mathrm{m}$.

C At $48 \mathrm{~h}$ post-infection, the viability of cells infected with MHV-A59 in the presence of intracellular or extracellular antiserum was determined by ATP luminescence assay. Increasing doses of antiserum results in increased cell survival.

D Kinetics of cell growth following MHV-A59 infection in the presence of a titration of electroporated anti-N antibody.

E Phase-contrast images of cells at $48 \mathrm{~h}$ post-infection. Scale bar $=200 \mu \mathrm{m}$.

$\mathrm{F} \quad$ Quantification of cell viability by ATP luminescence assay at $48 \mathrm{~h}$ post-infection in the presence of electroporated anti-N or anti-GFP antibodies.

C, H WT or TRIM21 KO L929 cells were infected with MHV-A59 in the presence of electroporated polyclonal antiserum (G) or anti-N antibody (H) and quantified by cell area $48 \mathrm{~h}$ later. Co-electroporation of protein $\mathrm{A} / \mathrm{G}$ with anti- $\mathrm{N}$ antibody into WT cells mimics the TRIM21 KO phenotype.

I $\quad$ L929 cells were infected with MHV-A59 for 4 h, and then, cyclohexamide (CHX) was added to block further viral protein synthesis. After 5 h, cells were electroporated with anti-N or anti-GFP antibodies and left for a further $3 \mathrm{~h}$ before being western blotted for cellular $\mathrm{N}$ protein levels ( ${ }^{*}$ denotes a non-specific band).

Data information: Data were analysed using a Student's $t$-test. Error bars depict the mean $+/$ - SEM. All data represent at least two independent replicates.

Source data are available online for this figure. 
we observed a significant reduction in production of new infectious particles in the presence of electroporated $\mathrm{N}$ antibodies (Fig 2B). Intracellular neutralization was antibody dose-dependent, consistent with the MHV data and previous ADIN experiments (McEwan et al, 2012) (Fig 2C and D). We next investigated whether intracellular neutralization of SARS-CoV-2 is TRIM21-dependent. We transduced a previously characterized TRIM21 knockout HEK293T clone with ACE2, to make it sensitive to SARS-CoV-2 entry, and then reconstituted TRIM21 expression with lentivirus encoding TRIM21 under its endogenous promoter or transduced with an empty vector control (Fig 2E; Zeng et al, 2019). Electroporation/infection experiments were then carried out as before in both cell lines. Neutralization of SARS-CoV-2 by N-antibody electroporation was observed by both
RT-qPCR (Fig 2F) and plaque assay (Fig 2G) but only in cells reconstituted with TRIM21. These results confirm that N-specific antibodies mediate TRIM21-dependent neutralization of SARS-CoV-2 and that EDNA can be used to quantify this activity.

\section{EDNA provides a functional assay for $\mathrm{N}$ antibodies in SARS-CoV-2 convalescent sera}

Anti-N antibodies reach high titres in many seroconverted individuals (preprint: Hachim et al, 2020) and are widely used as a diagnostic for previous infection with SARS-CoV-2 (Krammer \& Simon, 2020). However, there is no equivalent to an S-antibody neutralization test for $\mathrm{N}$. We therefore investigated whether EDNA could

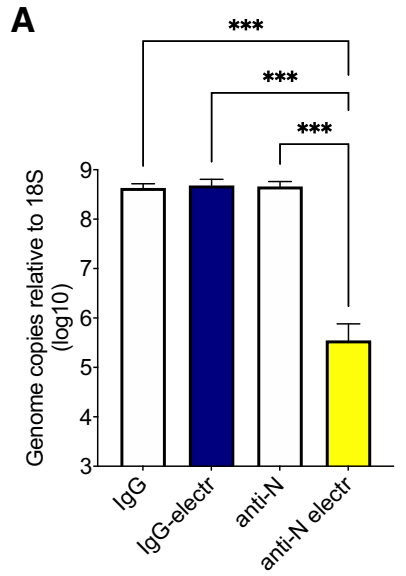

E

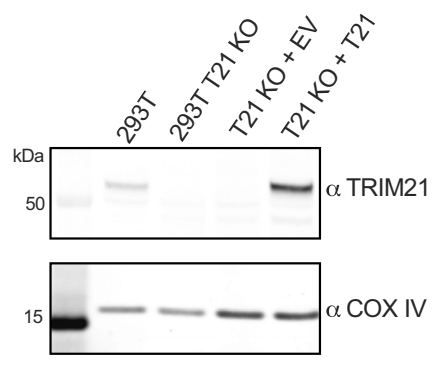

B

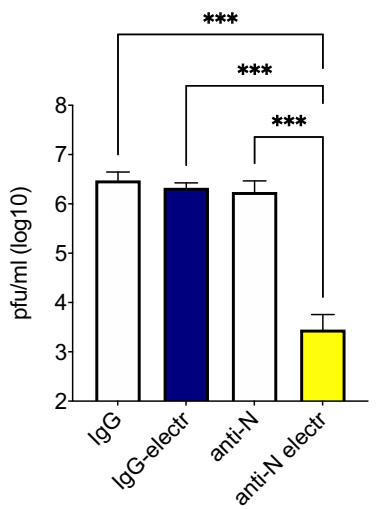

$\mathbf{F}$

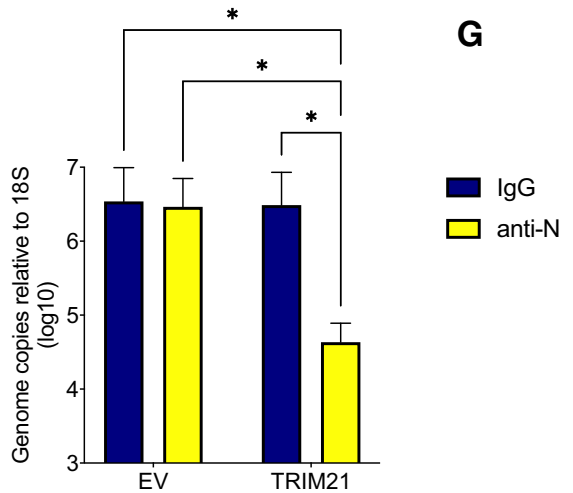

C

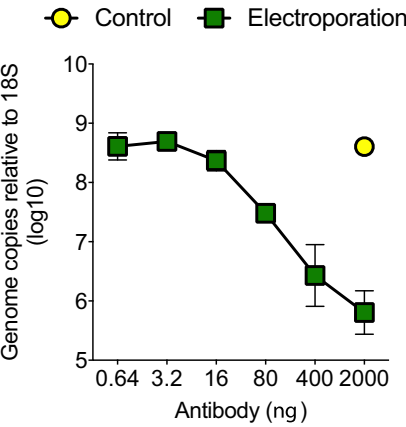

D

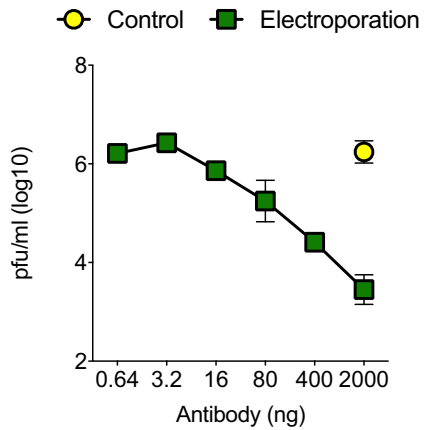

\section{Figure 2. $\mathrm{N}$ antibodies inhibit SARS-CoV-2 replication intracellularly.}

A, B Vero cells OE ACE2 and TMPRSS2 were infected with SARS-CoV-2 in the presence of IgG or anti-N antibodies added directly into media or electroporated into cells. Viral replication was then determined by RT-qPCR (A) or plaque assay (B). Electroporation of anti-N antibodies significantly inhibits SARS-CoV-2 replication $\left({ }^{* *} P<0.0002\right)$.

C, D As with A\&B, except with a titration of electroporated anti-N antibodies.

E Western blot of 293T cells and 293T ACE2 OE/TRIM21 KOs alone or reconstituted with empty vector (EV) or an endogenous promoter-driven TRIM21 vector (T21) (Zeng et al, 2019).

F, G 293T ACE2 OE/TRIM21 KO cells reconstituted with EV or TRIM21, electroporated with IgG or anti-N antibodies, and infected with SARS-CoV-2. Viral replication was then determined by RT-qPCR (F) or plaque assay (G). Electroporation of anti-N antibodies significantly inhibits SARS-CoV-2 replication only in TRIM21reconstituted cells $\left({ }^{\star} P<0.05\right)$.

Data information: All data represent at least three independent replicates. Error bars depict the mean \pm SEM. Statistical comparisons were performed using a one-way $(A, B)$ or two-way $(F, G)$ ANOVA.

Source data are available online for this figure. 
provide such an assay. We tested a small cohort of four SARS-CoV-2 convalescents (SARS-CoV-2 seropositivity confirmed by luminex testing) and two sero-negatives for their antibody responses using a capillary-based protein detection system (Jess, ProteinSimple). Jess measures native antibody-antigen binding, meaning that quantification of the chemiluminescent signal provides a measure analogous to the antibody titre obtained by ELISA (i.e. it is a combination of specific antibody concentration and affinity). We observed a range of responses; some sera displayed only limited reactivity to any SARS-CoV-2 antigen, others reacted robustly against $\mathrm{N}$ but weakly against $S$, and some had both strong anti-N/strong anti-S profiles (Fig $3 \mathrm{~A}$ and $\mathrm{B}$ ). The data show that a good dynamic range in antigen reactivity is capable of being measured but a larger cohort would be required to draw any conclusions about antibody portfolios. Next, we electroporated the sera into 293T ACE2 cells and infected them $24 \mathrm{~h}$ later with SARS-CoV-2. Infection levels were assessed after a further $24 \mathrm{~h}$ by plaque assay. Infection was decreased $>10$-fold in cells electroporated with sera that had a strong anti-N response (Fig 3C). In contrast, sera with essentially no anti-N antibodies were unable to neutralize infection. To establish whether activity in the polyclonal sera is dependent upon TRIM21, we compared infection in 293T TRIM21 KO ACE2 cells reconstituted with either empty vector or TRIM21. Only in TRIM21-reconstituted cells did electroporation of anti-N sera reduce infection (Fig 3D).
A
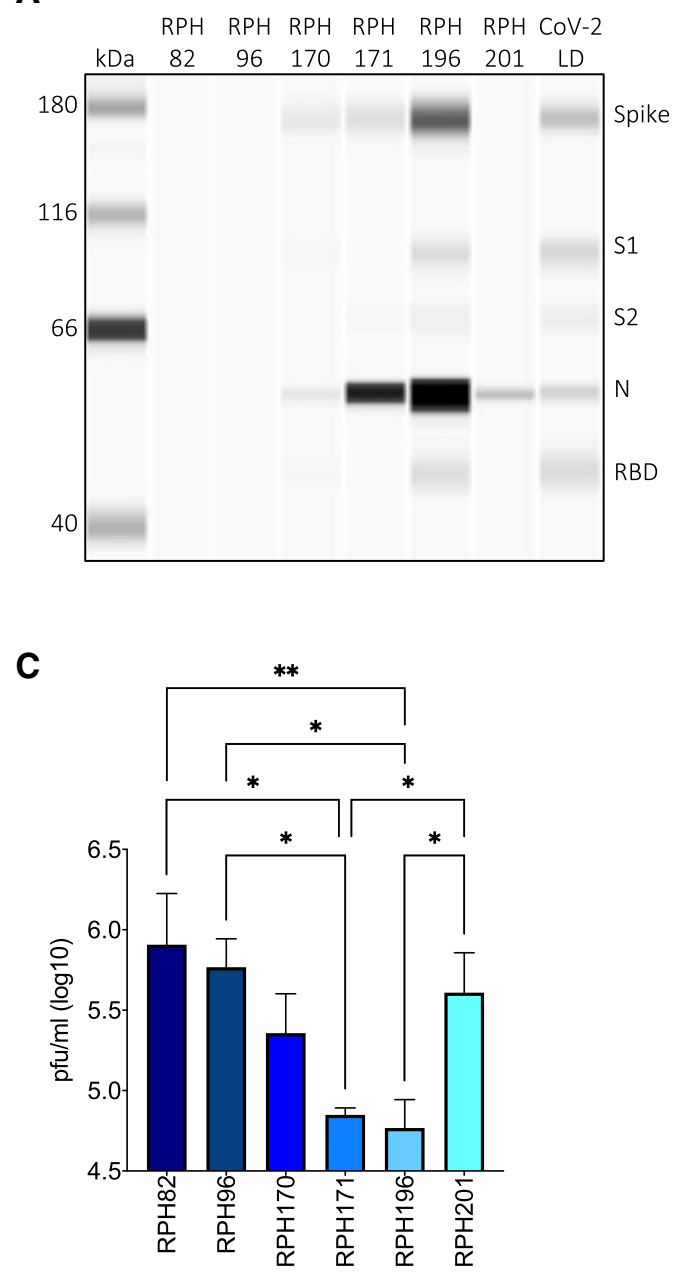

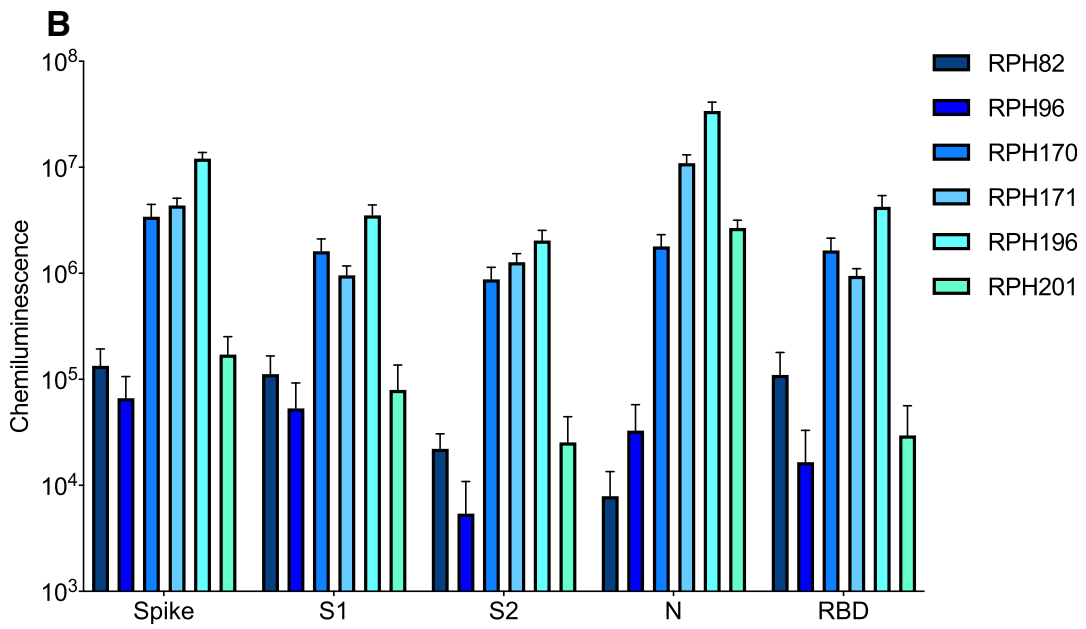

D

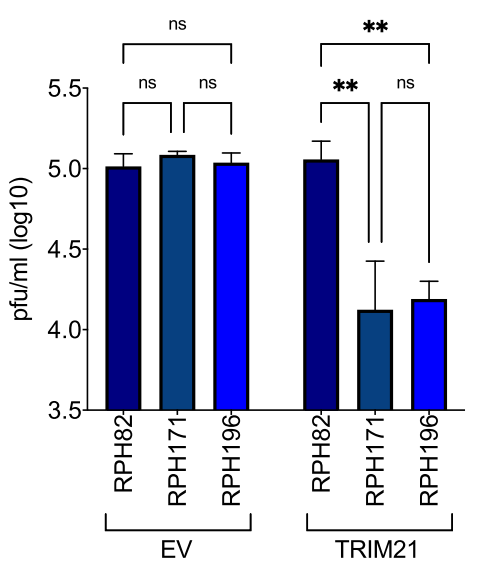

Figure 3. EDNA detects intracellular neutralization activity in SARS-CoV-2 convalescent sera.

A Capillary-based protein detection (Jess) of antibodies against SARS-CoV-2 antigens in convalescent sera.

B Quantification of antigen-specific antibodies in convalescent sera.

C 293 T cells OE ACE2 infected with SARS-CoV-2 in the presence of electroporated convalescent sera. There are statistically significant differences in the ability of serum from different individuals to inhibit viral replication intracellularly (** $P<0.005,{ }^{\star} P<0.05$ ).

D 293T ACE2 OE/TRIM21 KOs reconstituted with either empty vector (EV) or TRIM21-expressing vector (TRIM21) infected with SARS-CoV-2 in the presence of electroporated convalescent sera. Intracellular neutralization of viral replication is only observed in cells reconstituted with TRIM21 ( ${ }^{\star \star} P<0.005$ ).

Data information: All data represent at least three independent replicates. Error bars depict the mean \pm SEM. Statistical comparisons were performed using a one-way (C) or two-way (D) ANOVA. 


\section{SARS-CoV-2 convalescents make potently neutralizing anti-N antibodies and this correlates with increased levels of $\mathrm{N}$-specific $\mathrm{T}$ cells}

Having validated that EDNA could be used to assess convalescent serum samples, we collected a larger panel of sera from seroconverted staff at Royal Papworth Hospital NHS Foundation Trust (RPH), Cambridge University Hospitals NHS Foundation Trust (CUH) in Cambridge and The Queen Elizabeth Hospital NHS Foundation Trust (QEH) in Kings Lynn, UK. As before, we used Jess to quantify the antibody responses to N, S, S1, S2 and RBD (Fig 4A and Appendix Fig S2). There was a wide range in response strength, with chemiluminescence varying over $>4$-logs. Choosing two of the strongest responders to $\mathrm{N}$ protein, we performed a titration to establish the linear range of the binding assay (Appendix Fig S3). Sera containing particularly strong responses were diluted and remeasured to be within the linear range. The titration also confirmed that measured weak responders are still well above the threshold for detection. Performing a comparison between the antigens, we observed a weak correlation between anti-N and anti-S, S1, S2 or RBD responses ( $R^{2}$ between 0.17-0.32) (Appendix Fig S4A-D). Nevertheless, there was considerable variation with substantial numbers of individuals possessing monodominant responses (strong $\mathrm{N}$ or $\mathrm{S}$ but not both).

Next, we electroporated a single dilution of each serum into Vero ACE2/TMPRSS2 cells, challenged them with SARS-CoV-2 and quantified infection by RT-qPCR (Fig 4B). Comparing intracellular neutralization activity with antibody titres to each antigen in turn showed a trend between neutralization potency and strength of response to $\mathrm{N}$ but not to other antigens (Fig 4C and Appendix Fig $\mathrm{S} 2 \mathrm{~F}-\mathrm{I}$ ). This is consistent with the expected antigen topology upon viral entry, in which $\mathrm{S}$ antigen will remain at the plasma membrane following membrane fusion whilst $\mathrm{N}$ is delivered into the cytosol with the viral genome. To further confirm that it is anti-N and not anti-S antibodies that are responsible for the observed intracellular neutralization, we tested serum possessing a strong $\mathrm{S}$ /weak $\mathrm{N}$ antibody response (Appendix Fig S2A, Fig 4A) and confirmed that whilst it is unable to neutralize intracellularly, it potently neutralizes extracellularly (Appendix Fig S4E vs. Fig 4B). Whilst sera with the highest titre anti-N responses was usually the most strongly neutralizing, there were exceptions to this trend. Four serum samples possessed neutralization activity that was unexpectedly high given their modest anti-N titres, whilst one sample had a high anti-N titre but gave modest neutralization (Fig 4A-C; green and red bars, respectively). This may be because antibodies with unusually high affinity but present at low levels can exert a protective effect whilst conversely, specific antibodies present at high concentrations but with weak affinities may not. Comparison of the Jess and neutralization data also suggests that there is a threshold effect, in that neutralization is only observed in sera with a chemiluminescent signal $>10^{6}$ (Fig 4C). To determine whether this is due to the nature of the antibodies in these samples or whether there is a functional threshold for intracellular neutralization of SARS-CoV-2, we electroporated a titration of two potently neutralizing serum samples. We observed similar neutralization curves for both, indicating that once diluted to a chemiluminescent signal $<10^{6}$, neutralization activity is largely lost (Fig 4D and Appendix Fig S3). This suggests that there is indeed a functional threshold for intracellular neutralization of SARS-CoV-2.
Antibodies against internal antigens like nucleoprotein are generated during the immune response to most enveloped viruses (Schmaljohn, 2013). Importantly, although anti-N antibodies do not block infection when added directly to cultured cells in vitro, they provide protective immunity in vivo. This is likely because the antibodies are not efficiently taken up by cells in vitro, a step we bypass in EDNA by using electroporation. How anti-N antibodies are imported by cells in vivo and provide protection is not well understood. Recently, we showed that anti-N antibodies help to clear LCMV infection by promoting the induction of $\mathrm{N}$-specific cytotoxic $\mathrm{T}$ cells (Caddy et al, 2021). This is thought to occur as a result of cross-presentation: nucleoprotein immune complexes $(\mathrm{N}: \mathrm{Ab})$ are imported by antigen-presenting cells and detected by TRIM21, leading to proteasomal degradation and the generation of $\mathrm{N}$ peptides for MHC class I presentation. Both B and T cells responses contribute to SARS-CoV-2 immunity and almost all convalescents have both (Sette \& Crotty, 2021). We therefore considered that the same immune mechanism of antibody:T cell synergy we observed during LCMV infection may be operating during the response to SARS-CoV-2. To test this hypothesis, we isolated fresh PBMCs from SARS-CoV-2 convalescents and used ELISpot to quantify their N-specific T cells. Upon stimulation with an $\mathrm{N}$ peptide library, we observed a $\sim 100$-fold range in the number of specific (interferon expressing) cells between individuals (Fig 4E). Comparing the number of $\mathrm{N}$-specific $\mathrm{T}$ cells and intracellular neutralizing activity within each individual revealed a modest correlation, consistent with the hypothesis that $\mathrm{N}$ antibodies may contribute to protection against SARS-CoV-2 by promoting T-cell immunity (Fig 4F). Of note, a similar correlation performed using anti$\mathrm{N}$ binding titre failed to give a convincing correlation (Fig 4G). This result highlights the importance of measuring the neutralization activity of anti-N antibodies, not just their levels in serum, and the utility of EDNA.

\section{Discussion}

Here, we have described an in vitro assay called EDNA that can quantify the activity of $\mathrm{N}$ antibodies produced upon SARS-CoV-2 infection, in the same way that classical neutralization assays are used to quantify S-antibody activity (for overview, see Summary Figure). EDNA allows the measurement of $\mathrm{N}$-antibody activity in SARS-CoV-2 convalescent sera, can be used in conjunction with standard readouts like RT-qPCR and plaque assay and has a large dynamic range. EDNA uses electroporation to deliver antibodies directly into the cytoplasm of cells, before exposing them to virus. This allows antibodies that target antigens normally hidden inside the viral envelope to be tested for their ability to disrupt infection. Importantly, this means that antiviral activity can be detected in antibody sera that on the basis of low anti-S titres would normally be characterized as non-neutralizing (e.g. RPH38, CUH186, CUH066; Fig 4A and B, Appendix Fig S2A-D). Neutralizing antibodies typically work extracellularly by inhibiting receptor binding and/ or preventing fusion of the viral envelope with the cell membrane. In EDNA experiments with both MHV and SARS-CoV-2, and with both polyclonal sera and monoclonal anti- $\mathrm{N}$ antibodies, we show that intracellular neutralization is dependent upon the cytosolic Fc receptor and E3 ubiquitin ligase TRIM21. TRIM21 has previously been shown to mediate antibody-dependent intracellular 
A

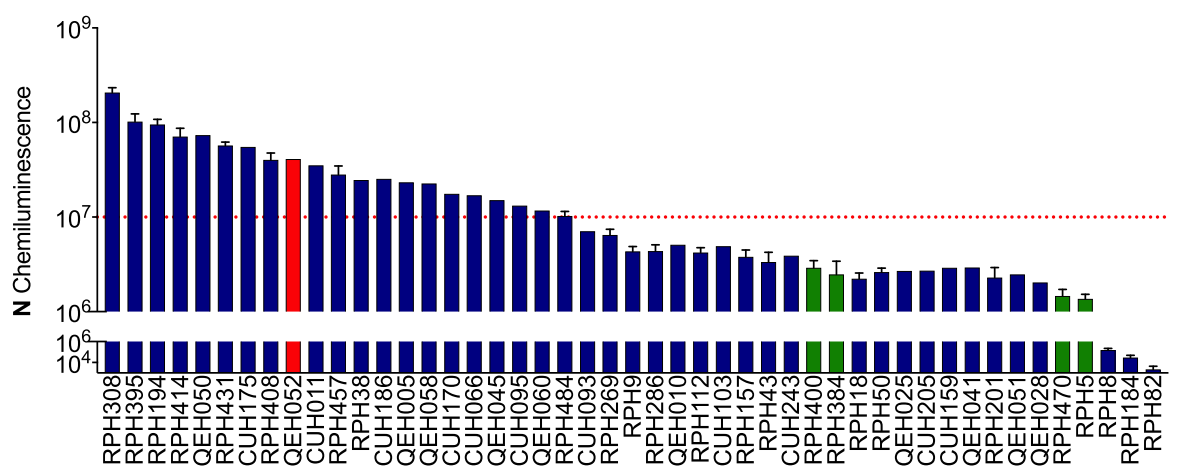

B

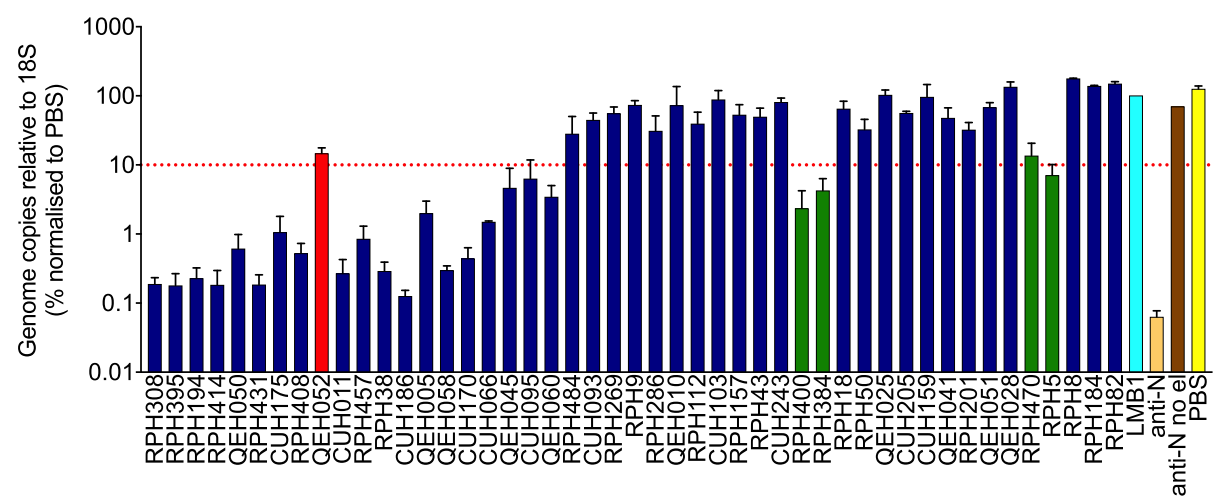

C

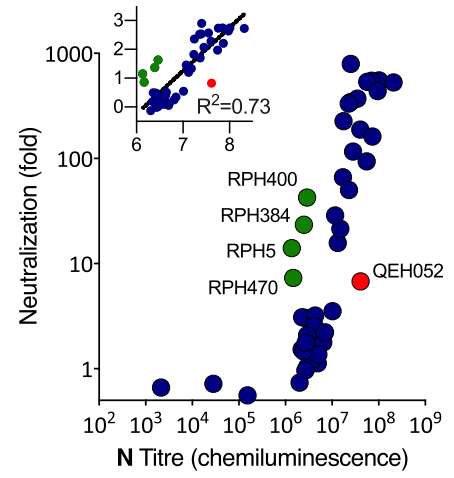

D

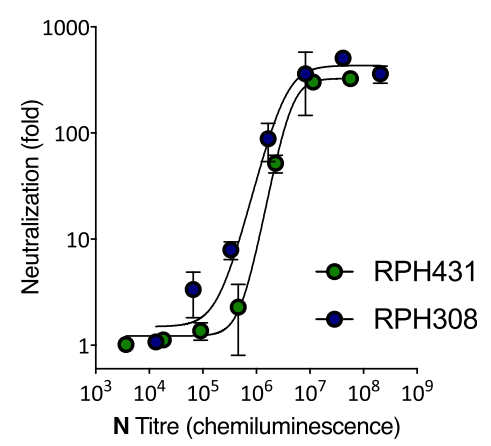

G

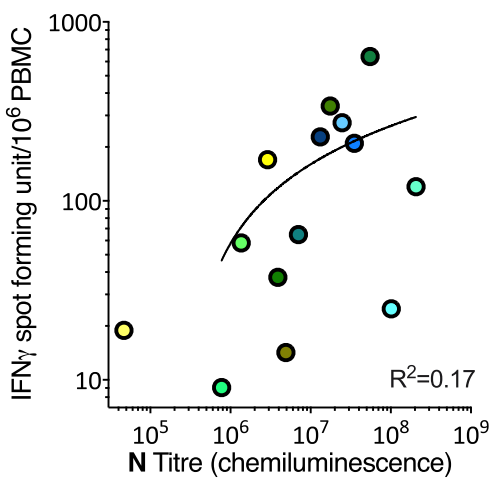

Figure 4. SARS-CoV-2 convalescents make potently neutralizing $\mathrm{N}$ antibodies whose activity correlates with the number of active $\mathrm{N}$-specific $\mathrm{T}$ cells.

A Capillary-based protein detection (Jess) of $\mathrm{N}$ antibodies in convalescent sera, quantified by chemiluminescence.

B Quantification of SARS-CoV-2 intracellular neutralization by electroporated convalescent sera using EDNA and RT-qPCR (as \% of PBS condition).

C Correlation between $\mathrm{N}$-antibody titre, as calculated by Jess, and intracellular neutralization (fold decrease in SARS-CoV-2 replication), as measured by EDNA, in convalescent sera from multiple individuals.

D Intracellular neutralization of SARS-CoV-2 by titrated serum from two strongly $\mathrm{N}$ antibody-positive individuals.

E ELISpot measuring IFN $\gamma$ production in T cells from SARS-CoV-2 convalescents upon stimulation with a peptide library covering N-protein.

$\mathrm{F}$ Correlation between $\mathrm{N}$-specific $\mathrm{T}$-cell activity and intracellular neutralization activity.

$\mathrm{G}$ Correlation between $\mathrm{N}$-specific T-cell activity and $\mathrm{N}$-antibody titre.

Data information: All data represent at least three independent replicates. Error bars depict the mean \pm SEM. Statistical analysis was performed using a semilog non-linear fit $(F, G)$.

neutralization (ADIN). In ADIN, antibodies pre-bound to a nonenveloped virus recruit TRIM21 to cause capsid degradation and we hypothesize that a similar mechanism of degradation operating against $\mathrm{N}$ protein blocks viral replication during EDNA. N protein protects the coronavirus genome and stabilizes sub-genomic RNA during viral transcription - so its degradation would be catastrophic 
for viral replication. Consistent with this, we observe $\mathrm{N}$ protein degradation during EDNA experiments with MHV, whilst in SARSCoV-2 experiments intracellular neutralization activity correlates with $\mathrm{N}$ antibody but not $\mathrm{S}$-antibody titre. $\mathrm{N}$-antibody binding titres are not always predictive of intracellular neutralizing capacity however, as sera can differ in titre by $>10$-fold but possess similar neutralization activity (e.g. RPH308 vs. CUH186; Fig 4A and B). Based on previous data, we predict that off-rates between antibodyantigen (Bottermann et al, 2016) and antibody-TRIM21 (Foss et al, 2016) will be predictive of intracellular neutralization potency. In contrast with extracellular entry-blocking neutralization, we expect epitope specificity to be less important as long as the epitope is present in the folded state and TRIM21 binding can take place.

Infection with most enveloped viruses results in high titre antibodies against internal antigens and whilst these are typically nonneutralizing in vitro (at least as characterized in standard assays) they are often highly protective in vivo (Schmaljohn, 2013). Based on our results here, and recently published (Caddy et al, 2021), we propose that ADIN may provide one underlying mechanism by which non-neutralizing antibodies mediate protection. However, ADIN does not explain how and where non-neutralizing antibodies like those against $\mathrm{N}$ protein meet their antigen. EDNA is an in vitro assay in which antibodies are artificially delivered directly into the cytosol. This is a limitation of the method and does not address the issue of cellular uptake and cytosolic import during natural SARSCoV-2 infection in vivo. Whilst antibodies are readily taken up by most tissues, they are normally recycled back out of the cell by the neonatal Fc receptor FcRn. There is evidence that antibodies can be imported into the cytosol, typically during disease, but the mechanisms involved are unclear (Congdon et al, 2013). Indeed, it is the absence of a well-understood mechanism to explain how antibodies against internal viral antigens like the nucleoprotein meet their target has discouraged study into their role in protective immunity.

The context in which cytosolic antibody import is best understood is during antigen presentation, where both passive mechanisms involving membrane disruption and leakage into the cytosol (Reis e Sousa \& Germain, 1995) and active mechanisms of import requiring the channel forming protein Sec61 (Mukai et al, 2011) and the ATPase VCP (Ackerman et al, 2006) have been proposed. Most recently, the receptor DNGR-1 has been shown to promote phagosomal rupture by inducing NADPH oxidase activity (Canton et al, 2021). Previous work on viruses such as influenza has demonstrated a synergistic link between $\mathrm{N}$-specific antibodies and N-specific cytotoxic T lymphocytes (CTLs; LaMere et al, 2011; Laidlaw et al, 2013). Moreover, we recently showed that TRIM21 uses anti-N antibodies to promote $\mathrm{N}$-specific CTLs and thereby protect against LCMV infection (Caddy et al, 2021). These data suggested that TRIM21 can detect immune complexes upon their import into antigen-presenting cells and cause their rapid proteasomal degradation, leading to the efficient generation of peptides for MHC class I presentation. We hypothesize that a similar process may be operating during SARS-CoV-2 infection. Consistent with this, we find a correlation between $\mathrm{N}$-antibody neutralization as measured by EDNA and N-specific T cells as measured by ELISpot. Convalescents with potently neutralizing $\mathrm{N}$ antibodies possess increased numbers of $\mathrm{N}$-specific $\mathrm{T}$ cells. Moreover, we observed individuals (e.g. RPH38; Fig 4A, B, E and Appendix Fig S2A) with low $S$ titres but both strong anti-N neutralization and high numbers of $\mathrm{N}$-specific $\mathrm{T}$ cells. There may be differences in the immediate protection afforded by $\mathrm{N}$ - vs S-directed B- and T-cell immunity. Perhaps more importantly, the longevity of responses to each antigen may differ as could their ability to protect against new viral variants. Notably, $\mathrm{N}$-specific T-cell responses in SARS$\mathrm{CoV}$ convalescents could be detected 17 years after infection (Le Bert et al, 2020) and were cross-reactive with $\mathrm{N}$ from SARS-CoV-2. Whilst our findings require further validation in larger cohorts, and in studies correlating responses with patient outcomes, they provide evidence both of the utility of EDNA and the importance of considering $\mathrm{N}$-based vaccines as a viable alternative to S-only approaches.

\section{Materials and Methods}

Reagents and Tools table

\begin{tabular}{lll}
\hline Reagent/Resource & Reference or Source & Identifier or catalog number \\
\hline Experimental models & & \\
\hline Vero CCL-81 & ATCC & CCL-81 \\
\hline HEK293T & ATCC & CRL-3216 \\
\hline L929 & ATCC & CCL-1 \\
\hline Vero ACE2/TMPRSS2 & Papa et al (2021) & Vero ACE2/TMPRSS2 \\
\hline HEK293T ACE2 & Papa et al (2021) & HEK293T ACE2 \\
\hline SARS-CoV-2/human/Liverpool/REMRQ0001/2020 & Papa et al (2021) & Kind gift from Lance Turtle (University of Liverpool) \\
& & and David Matthews and Andrew Davidson (University \\
& & of Bristol) \\
\hline MHV-A59 & & Kind gift from lan Goodfellow (Cambridge University) \\
\hline Antibodies & & \\
\hline $\begin{array}{l}\text { MHV-A59 polyclonal antiserum raised against disintegrated, } \\
\text { purified MHV-A59 virions (Rottier et al, 1981) }\end{array}$ & $\begin{array}{l}\text { Dr. Peter Rottier (Utrecht } \\
\text { University). }\end{array}$ & MHV-A59 polyclonal antiserum \\
\hline
\end{tabular}


Reagents and Tools table (continued)

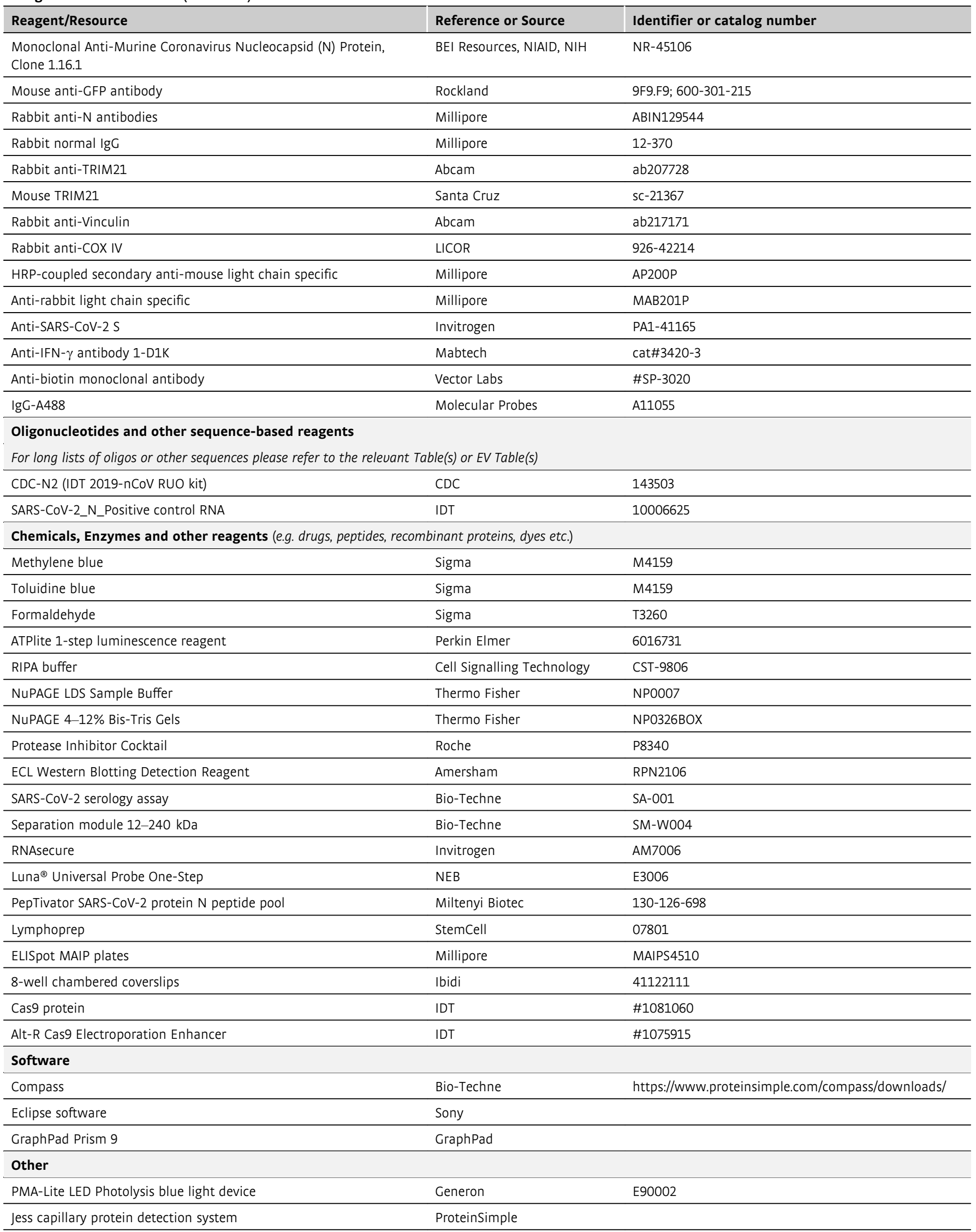


Reagents and Tools table (continued)

\begin{tabular}{lll}
\hline Reagent/Resource & Reference or Source & Identifier or catalog number \\
\hline Neon Transfection System & Thermo Fisher & MPK5000 \\
\hline IncuCyte S3 & Sartorius & \\
\hline ABI StepOnePlus PCR System & Life Technologies & \\
\hline ELISpot reader & AID ispot, Autoimmun & \\
& Diagnostika & \\
\hline Eclipse EC800 flow cytometer & Sony & \\
\hline Lumascope LS720 widefield microscope & Etaluma & \\
\hline PHERAstar FS plate reader & BMC &
\end{tabular}

\section{Methods and Protocols}

\section{MHV EDNA}

1 Wash cells (e.g. Vero ACE2/TMPRSS2) in PBS and resuspend in Buffer R (Thermo Fisher) at a concentration of between 0.1$1 \times 10^{8}$ cells $\mathrm{ml}^{-1}$ depending on experiment.

2 For each electroporation reaction, mix $0.1-1 \times 10^{6}$ cells $(10.5 \mu \mathrm{l})$ with $2 \mu \mathrm{l}$ of the antibody/serum/protein to be delivered.

3 Take up electroporation mixture into a $10-\mu 1$ Neon Pipette Tip and electroporate using a Neon Electroporator using the following settings: $1,400 \mathrm{~V}, 20 \mathrm{~ms}, 2$ pulses. For nonelectroporated controls, skip this step.

4 Transfer electroporated cells to medium supplemented with $10 \%$ serum without antibiotics.

5 Plate $1 \times 10^{4}$ electroporated L929 cells in 96-well plates in triplicates. The next day, infect cells with MHV-A59 at MOI $=1$.

6 Image using an IncuCyte system for $48 \mathrm{~h}$ within a $37^{\circ} \mathrm{C}, 5 \%$ $\mathrm{CO}_{2}$ humidified incubator.

$7 \quad$ Quantify total cell area using IncuCyte software by detecting the outline of cells. Mock-infected cells (no virus) will rapidly proliferate to form a confluent monolayer over the course of 48 h (Appendix Fig S1A).

8 Check for a typical cell growth curve consisting of a short lag phase followed by logarithmic growth and then a stationary phase as the cells formed a confluent monolayer. In contrast, cells infected with MHV-A59 should begin to fuse after 8-10 h, and by $30 \mathrm{~h}$ post-infection large syncytia occupy the majority of the monolayer. Between 30 and $48 \mathrm{~h}$ post-infection, the syncytia should have lysed and detached from the dish and the remaining cells exhibited a rounded morphology typical of dead of dying cells. The cell growth curves should show an incremental shift towards the no virus control with each serial dilution of viral stock (Appendix Fig S1B, circles - black to grey to white). Plotting the cell area values at $48 \mathrm{~h}$ postinfection against virus dilution should give a typical doseresponse curve that can be fitted with a non-linear regression curve to calculate a TCID50 value (in our case, $2.12 \times 10^{8}$ TCID50/ml; Appendix Fig S1C).

9 After imaging is completed, the same cells should be analysed by ATP luminescence assay at $48 \mathrm{~h}$ post-infection to quantify cell viability.

10 For ATP assay, cells in $100 \mu$ l media in dark 96-well plates should be lysed with $100 \mu \mathrm{l} /$ well of ATPlite 1-step luminescence reagent according to manufacturer instructions.
11 Quantify luminescence using a luminometer (e.g. BMG PHERAstar FS plate reader). Plotting these values against virus dilution should give an almost identical dose-response curve and TCID50 value (Appendix Fig S1D).

\section{SARS-COV-2 EDNA}

1 Wash cells (e.g. Vero ACE2/TMPRSS2) in PBS and resuspend in Buffer R (Thermo Fisher) at a concentration of between 0.1$1 \times 10^{8}$ cells $\mathrm{ml}^{-1}$ depending on experiment.

2 For each electroporation reaction, mix $0.1-1 \times 10^{6}$ cells $(10.5 \mu \mathrm{l})$ with $2 \mu \mathrm{l}$ of the antibody/serum to be delivered.

3 Take up electroporation mixture into a $10 \mu$ l Neon Pipette Tip and electroporate using a Neon Electroporator using the following settings: $1,400 \mathrm{~V}, 20 \mathrm{~ms}, 2$ pulses. For nonelectroporated controls, skip this step.

4 Transfer electroporated cells to medium supplemented with $10 \%$ serum without antibiotics.

5 Seed $1.5 \times 10^{4}$ electroporated cells into 96-well plates in triplicates for RT-qPCRs or $2.5 \times 10^{5}$ cells into 24-well plates for plaque assays. After $24 \mathrm{~h}$, transfer plates to containment level 3 laboratory (CL3).

6 Remove supernatants and wash wells with PBS to remove remaining antibodies that could interfere with the virus entry process.

7 At CL3, infect cells at moi $=1$ in DMEM supplemented with $2 \%$ FBS and antibiotics.

8 Assess viral RNA loads or production of viral particles after $24 \mathrm{~h}$ incubation to allow for single replication cycle (see below). Plates should be immediately frozen after incubation. For plaque assays, cells should be freeze/thawed three times to ensure virions are released.

9 To compare EDNA with classical extracellular neutralization, incubate sera directly with virus at a range of pfu for $1 \mathrm{~h}$ before adding to cells for $24 \mathrm{~h}$. Assess neutralization by following step 8 above.

\section{Plaque assay for SARS-CoV-2}

10 -fold serial dilutions of viral supernatants were prepared and used to infect monolayers of Vero ACE2/TMPRSS2 cells. After $1 \mathrm{~h}$ of incubation, wells were overlayed with DMEM containing $2 \%$ FBS, antibiotics and $0.05 \%$ agarose. Cells were incubated for 3 days, fixed with $4 \%$ formaldehyde and stained with $0.1 \%$ toluidine blue. 


\section{RT-qPCR assay for SARS-CoV-2}

After incubation plates were immediately frozen at $-70^{\circ} \mathrm{C}$ to help with cell lysis. Next, plates were thawed at $4^{\circ} \mathrm{C}$ and 1 volume of lysis buffer $(0.25 \%$ Triton X-100, $50 \mathrm{mM} \mathrm{KCl,} 100 \mathrm{mM}$ Tris- $\mathrm{HCl} \mathrm{pH}$ 7.4 , glycerol $40 \%$ and RNAsecure $(1 / 100)$ added to wells and mixed gently by pipetting up and down few times. After 5 min of lysis, cell lysates were transferred to PCR plates and virus inactivated at $95^{\circ} \mathrm{C}$ for 5 min. RT-qPCR were performed with Luna ${ }^{\circledR}$ Universal Probe One-Step kit following manufacturer recommendations. Primer/ probe for genomic viral RNA were CDC-N2. Primer probe for $18 \mathrm{~S}$ control were described previously (Ashraf et al, 2006). SARS-CoV2_N_Positive control RNA was used as standard for the viral genomic $\mathrm{N}$ reactions. For $18 \mathrm{~S}$ standard, DNA was synthesized and kindly gifted by Jordan Clarks and James Stewart (University of Liverpool). Final concentrations of $500 \mathrm{nM}$ for each primer and $125 \mathrm{nM}$ for the probe were used. RT-qPCRs were run on ABI StepOnePlus PCR System with following program: $55^{\circ} \mathrm{C}$ for $10 \mathrm{~min}, 95^{\circ} \mathrm{C}$ for $1 \mathrm{~min}$ and then 40 cycles of $95^{\circ} \mathrm{C}$ denaturation for $10 \mathrm{~s}$ and $60^{\circ} \mathrm{C}$ extension for $30 \mathrm{~s}$. RNA copy numbers were obtained from standards and then genomic copies of $\mathrm{N}$ normalized to $10^{10}$ copies of 18 S. Finally, all data were normalized to $100 \%$ negative control.

\section{Generation of TRIM21 KO cells}

L929 TRIM21 KO cells were generated using the Alt-R CRISPR-Cas9 system from Integrated DNA technologies (IDT) with a predesigned crRNA sequence (GAGCCTATGAGTATCGAATG). Guide RNA in the form of crRNA-tracrRNA duplex was assembled with recombinant Cas9 protein and electroporated into L929 cells together with Alt-R Cas9 Electroporation Enhancer. Two days post-electroporation polyclonal cells were expanded and also plated one cell per well in 96well plates to select single cell clones screened by Western blotting for TRIM21 protein.

\section{SARS-CoV-2 virus preparation}

Virus stock was generated in Vero ACE2/TMPRSS2 cells by infecting cells at low moi of 0.05 and incubating for three days. Supernatants were freeze/thawed three times, aliquoted and stored at $-70^{\circ} \mathrm{C}$. Titres were assessed by plaque assay. MHV-A59 virus was a kind gift from Ian Goodfellow (University of Cambridge).

\section{Western blotting}

Cells were washed in PBS, lysed in RIPA buffer (CST-9806) or $1 \%$ Triton X-100 supplemented with a protease inhibitor cocktail, spun at $14,000 \mathrm{~g}$ for $10 \mathrm{~min}$ and cleared lysates mixed with NuPAGE LDS Sample Buffer and heated at $95^{\circ} \mathrm{C}$ for $5 \mathrm{~min}$. Samples were run on NuPAGE 4-12\% Bis-Tris gels and transferred onto nitrocellulose membrane. For Western blotting of MHV-A59, MHV-A59 polyclonal antiserum was used that was raised against disintegrated, purified MHV-A59 virions (Rottier et al, 1981). The serum detects multiple viral proteins by immunoblot that likely represent the entire MHVA59 proteome. Prominent bands at $\sim 180, \sim 90$ and $\sim 50 \mathrm{kDa}$ likely correspond to full-length spike (S), cleaved spike and nucleoprotein $(\mathrm{N})$, respectively (Appendix Fig S1E). Antibody incubations were rabbit anti-MHV serum $(1: 5,000)$, mouse anti-MHV $\mathrm{N}$ protein $(1: 2,000)$, rabbit anti-TRIM21 $(1: 1,000)$ or mouse TRIM21 $(1: 1,000)$, rabbit anti-Vinculin $(1: 50,000)$ and rabbit COX IV antibodies $(1: 5,000)$. HRP-coupled secondary anti-mouse light chain-specific and anti-rabbit light chain-specific antibodies were detected by enhanced chemiluminescence. For fluorescent detection, we used secondary antibodies from LICOR and LICOR Odyssey detection device.

\section{Serum and cell samples}

Staff from RPH were recruited through staff email over the course of 2 months: 20 April 2020-10 June 2020, as part of a prospective study to establish seroprevalence and immune correlates of protective immunity to SARS-CoV-2 (Ethics Approval: HRA IRAS: 96194 REC: 12/WA/0148). Staff from CUH and QEH were recruited through the COVID-19 Serology in Oncology Staff (CSOS) study (Favara et al, 2021a; Favara et al, 2021b) with samples collected in June, July and December 2020 (Ethics approval: HRA IRAS: 284231). Samples were screened for SARS-CoV-2 N and S binding antibodies by Luminex assay as previously described (Kemp et al, 2021) and selected for further investigation based on selective binding profiles.

\section{Serum inactivation}

Human serum samples from RPH were inactivated by methylene blue photochemical treatment. For that, methylene blue was added to sera at final concentration of $4 \mu \mathrm{M}$ and illuminated for $15 \mathrm{~min}$ with PMA-Lite LED Photolysis blue light device. Serum samples from $\mathrm{CUH}$ and $\mathrm{QEH}$ were heat inactivated at $56^{\circ} \mathrm{C}$ for $30 \mathrm{~min}$.

\section{Detection and quantification of anti-SARS-CoV-2 antibodies}

Inactivated human serum was run on Jess capillary protein detection system. Serum samples were diluted $20 \times$ for the first test. Higher or lower dilutions were used for consequent runs depending on antibody signal. To detect S-, S1-, S2-, N- and RBS-specific antibodies, we used SARS-CoV-2 serology assay and separation module $12-240 \mathrm{kDa}$. Samples were run following manufacturers protocol. Shortly, protein standard is run in each capillary and in the presence of specific human antibodies these serve as primary antibodies that are then detected with anti-human HRP secondary antibody. BioTechne software Compass was used to quantify antibody titres in the samples.

\section{PBMC isolation and ELISpot}

PBMCs were isolated from whole blood collected into Lymphoprep. ELISpot plates containing PVDF membranes were activated with $15 \mu \mathrm{l}$ of $35 \%$ ethanol for $30 \mathrm{~s}$ and washed with distilled water. Plates were then coated overnight at $4^{\circ} \mathrm{C}$ with $100 \mu \mathrm{l}$ of monoclonal antibodies against IFN- $\gamma 5 \mu \mathrm{g} / \mathrm{ml}$ of clone 1-D1K. ELISpot plates were washed and then blocked with $200 \mu \mathrm{l} \mathrm{R}-10$ media for at least 3 h. R-10 media: RPMI 1640 supplemented with $10 \%$ (v/v), FBS, $2 \mathrm{mM}$ L-glutamine, 100 units penicillin, $0.1 \mathrm{mg} / \mathrm{ml}$ streptomycin, $10 \mathrm{mM}$ HEPES buffer and $1 \mathrm{mM}$ sodium pyruvate. At the end of incubation media was discarded and triplicates of 200,000 peripheral blood mononuclear cells (PBMCs) were grown in the presence or absence of $\mathrm{N}$ peptide pool at $1.5 \mu \mathrm{g} / \mathrm{ml}$ final concentration in $100 \mu \mathrm{l}$ of R-10 media. The peptide mix covers the whole sequence of the nucleocapsid phosphoprotein. After $16 \mathrm{~h}$ of incubation at $37^{\circ} \mathrm{C}$, the ELISpot plate was washed followed by incubation with $50 \mu$ biotinylated mouse anti-human IFN $\gamma$ monoclonal antibody 7-B6-1 diluted to $0.5 \mu \mathrm{g} / \mathrm{ml}$ in $0.5 \%$ BSA/PBS for $3 \mathrm{~h}$. Captured IFN $\gamma$ was detected with $50 \mu \mathrm{l}$ of anti-biotin monoclonal antibody, diluted $1: 750 \mathrm{ml}$ in $0.5 \% \mathrm{BSA} / \mathrm{PBS}$. After $2 \mathrm{~h}$, plate was washed, 
$50 \mu \mathrm{l}$ of nitro blue tetrazolium/5-bromo-4-chloro-3-indolyl-phosphate was added; purple spots appeared within 10 min. Spot numbers were analysed by an ELISpot reader. Frequencies of Cov-2 Spikespecific IFN $\gamma$ producing cells were calculated by subtracting the number of detected spots in the unstimulated sample from the number of spots detected in the presence of PepTivator SARS-CoV-2 protein $\mathrm{N}$ peptide pool (average of triplicates) and were given as IFN $\gamma$ spot forming cells $(\mathrm{SFC}) / 1 \times 10^{6} \mathrm{PBMC}$.

\section{Flow cytometry}

Electroporated fluorescent antibody (IgG-A488) was detected using an Eclipse EC800 flow cytometer after fixing cells with $4 \%$ formaldehyde at $1 \mathrm{~h}$ post-electroporation. Flow cytometry data were analysed using Eclipse software to obtain mean fluorescence intensity for the entire cell population as well as \% cells IgG-A488 positive by gating against cells electroporated with just PBS.

\section{Microscopy}

Cells electroporated with IgG-A488 were washed in fresh media to remove undelivered antibody and plated on 8-well chambered coverslips. Cellular IgG-A488 was detected using a Lumascope LS720 widefield microscope equipped with a $40 \times 0.95 \mathrm{NA}$ air objective, housed within a $37^{\circ} \mathrm{C}, 5 \% \mathrm{CO}_{2}$ humidified incubator.

\section{Statistical analysis}

Unless otherwise indicated, statistical analyses were performed using GraphPad Prism 9 software (GraphPad) employing one-way and two-way ANOVA and least squares fits. Error bars depict the mean \pm SEM unless indicated otherwise.

\section{Data availability}

This study includes no data deposited in external repositories.

Expanded View for this article is available online.

\section{Acknowledgements}

We are grateful to Dr. Peter Rottier of Utrecht University for reagents and advice on MHV-A59. This work was supported by MRC U105181010 (LCJ), Wellcome Trust Investigator Award 200594/Z/16/Z (LCJ), Wellcome Trust Collaborator Award 214344/A/18/Z (LCJ).

\section{Author contributions}

Conceptualization: LCJ. Methodology: LC], AA, DC, MV, TR, DMF, HEB, SLC. Investigation: AA, DC, MV, TR, DMF, HEB. Analysis: LCJ, AA, DC, MV. Writing original draft: $L C$, AA, DC. Writing - review and editing: LCJ, AA, DC, MV, TR, DMF, HEB

\section{Conflict of interest}

The authors declare that they have no conflict of interest.

\section{References}

Ackerman AL, Giodini A, Cresswell P (2006) A role for the endoplasmic reticulum protein retrotranslocation machinery during crosspresentation by dendritic cells. Immunity 25: 607-617
Ashraf N, Zino S, Macintyre A, Kingsmore D, Payne AP, George WD, Shiels PG (2006) Altered sirtuin expression is associated with node-positive breast cancer. Br J Cancer 95: 1056-1061

Avanzato VA, Matson MJ, Seifert SN, Pryce R, Williamson BN, Anzick SL, Barbian K, Judson SD, Fischer ER, Martens C et al (2020) Case study: prolonged infectious SARS-CoV-2 shedding from an asymptomatic immunocompromised individual with cancer. Cell 183: 1901-1912

Bootz A, Karbach A, Spindler J, Kropff B, Reuter N, Sticht H, Winkler TH, Britt WJ, Mach M (2017) Protective capacity of neutralizing and nonneutralizing antibodies against glycoprotein B of cytomegalovirus. PLOS Pathog 13: e1006601

Bottermann M, Lode HE, Watkinson RE, Foss S, Sandlie I, Andersen JT, James LC (2016) Antibody-antigen kinetics constrain intracellular humoral immunity. Sci Rep 6: 37457

Caddy SL, Vaysburd M, Papa G, Wing M, O'Connell K, Stoycheva D, Foss S, Terje Andersen J, Oxenius A, James LC (2021) Viral nucleoprotein antibodies activate TRIM21 and induce T cell immunity. Embo J 40: e106228

Canton J, Blees H, Henry CM, Buck MD, Schulz O, Rogers NC, Childs E, Zelenay S, Rhys H, Domart M-C et al (2021) The receptor DNGR-1 signals for phagosomal rupture to promote cross-presentation of dead-cellassociated antigens. Nat Immunol 22: 140-153

Carragher DM, Kaminski DA, Moquin A, Hartson L, Randall TD (2008) A novel role for non-neutralizing antibodies against nucleoprotein in facilitating resistance to influenza virus. J Immunol 181: 4168-4176

Clift D, McEwan WA, Labzin LI, Konieczny V, Mogessie B, James LC, Schuh M (2017) A method for the acute and rapid degradation of endogenous proteins. Cell 171: $1692-1706$

Congdon EE, Gu J, Sait HB, Sigurdsson EM (2013) Antibody uptake into neurons occurs primarily via clathrin-dependent Fcgamma receptor endocytosis and is a prerequisite for acute tau protein clearance. $J$ Biol Chem 288: $35452-35465$

Excler JL, Ake J, Robb ML, Kim JH, Plotkin SA (2014) Nonneutralizing functional antibodies: a new "old" paradigm for HIV vaccines. Clin Vaccine Immunol 21: 1023-1036

Favara DM, Cooke A, Doffinger R, McAdam K, Corrie P, Ainsworth NL (2021a) COVID-19 serology in oncology staff study: understanding SARS-CoV-2 in the oncology workforce. Clin Oncol 33: e61-e63

Favara DM, McAdam K, Cooke A, Bordessa-Kelly A, Budriunaite I, Bossingham S, Houghton S, Doffinger R, Ainsworth N, Corrie P (2021b) SARS-CoV-2 antigen and antibody prevalence among UK staff working with cancer patients during the COVID-19 pandemic. Clin Oncol (R Coll Radiol) https:// doi.org/10.1101/2020.09.18.20197590

Foss S, Watkinson RE, Grevys A, McAdam MB, Bern M, Høydahl LS, Dalhus B, Michaelsen TE, Sandlie I, James LC et al (2016) TRIM21 Immune Signaling Is More Sensitive to Antibody Affinity Than Its Neutralization Activity. J Immunol 196: 3452-3459

Garcia-Beltran WF, Lam EC, St Denis K, Nitido AD, Garcia ZH, Hauser BM, Feldman J, Pavlovic MN, Gregory DJ, Poznansky MC et al (2021) Circulating SARS-CoV-2 variants escape neutralization by vaccine-induced humoral immunity. medRxiu https://doi.org/10.1101/2021.02.14.21251704 [PREPRINT]

Hachim A, Kavian N, Cohen CA, Chin AW, Chu DK, Mok CKP, Tsang OT, Yeung YC, Perera RA, Poon LL et al (2020) Beyond the Spike: identification of viral targets of the antibody response to SARS-CoV-2 in COVID-19 patients. medRxiu https://doi.org/10.1101/2020.04.30.20085670 [PREPRINT]

Hauler F, Mallery DL, McEwan WA, Bidgood SR, James LC (2012) AAA ATPase p97/NCP is essential for TRIM21-mediated virus neutralization. Proc Natl Acad Sci USA 109: 19733-19738 
James LC, Keeble AH, Khan Z, Rhodes DA, Trowsdale J (2007) Structural basis for PRYSPRY-mediated tripartite motif (TRIM) protein function. Proc Natl Acad Sci USA 104: 6200-6205

Keeble AH, Khan Z, Forster A, James LC (2008) TRIM21 is an IgC receptor that is structurally, thermodynamically, and kinetically conserved. Proc Natl Acad Sci USA 105: 6045-6050

Kemp SA, Collier DA, Datir RP, Ferreira IATM, Gayed S, Jahun A, Hosmillo M, Rees-Spear C, Mlcochova P, Lumb IU et al (2021) SARS-CoV-2 evolution during treatment of chronic infection. Nature 592: 277-282

Kiss L, Clift D, Renner N, Neuhaus D, James LC (2021) RING domains act as both substrate and enzyme in a catalytic arrangement to drive selfanchored ubiquitination. Nat Commun 12: 1220

Krammer F, Simon V (2020) Serology assays to manage COVID-19. Science 368: 1060-1061

Laidlaw BJ, Decman V, Ali M-A, Abt MC, Wolf Al, Monticelli LA, Mozdzanowska K, Angelosanto JM, Artis D, Erikson J et al (2013) Cooperativity between CD8+ T cells, non-neutralizing antibodies, and alveolar macrophages is important for heterosubtypic influenza virus immunity. PLoS Pathog 9: e1003207

LaMere MW, Lam HT, Moquin A, Haynes L, Lund FE, Randall TD, Kaminski DA (2011) Contributions of antinucleoprotein IgC to heterosubtypic immunity against influenza virus. J Immunol 186: $4331-4339$

Le Bert N, Tan AT, Kunasegaran K, Tham CYL, Hafezi M, Chia A, Chng MHY, Lin M, Tan N, Linster M et al (2020) SARS-CoV-2-specific T cell immunity in cases of COVID-19 and SARS, and uninfected controls. Nature 584: $457-462$

Lecomte J, Cainelli-Gebara V, Mercier G, Mansour S, Talbot PJ, Lussier G, Oth D (1987) Protection from mouse hepatitis virus type 3-induced acute disease by an anti-nucleoprotein monoclonal antibody. Brief report. Arch Virol 97: $123-130$

Leibowitz JL, DeVries JR, Rodriguez M (1987) Increased hepatotropism of mutants of MHV, strain JHM, selected with monoclonal antibodies. Adv Exp Med Biol 218: 321-331

Li K, Huang B, Wu M, Zhong A, Li Lu, Cai Y, Wang Z, Wu L, Zhu M, Li J et al (2020) Dynamic changes in anti-SARS-CoV-2 antibodies during SARS-CoV-2 infection and recovery from COVID-19. Nat Commun 11: 6044

Mallery DL, McEwan WA, Bidgood SR, Towers GJ, Johnson CM, James LC (2010) Antibodies mediate intracellular immunity through tripartite motifcontaining 21 (TRIM21). Proc Natl Acad Sci USA 107: 19985-19990

Mayr LM, Su B, Moog C (2017) Non-neutralizing antibodies directed against HIV and their functions. Front Immunol 8: 1590

McCallum M, Bassi J, Marco A, Chen A, Walls AC, Iulio JD, Tortorici MA, Navarro MJ, Silacci-Fregni C, Saliba C et al (2021) SARS-CoV-2 immune evasion by variant B.1.427/B.1.429. bioRxiu https://doi.org/10.1101/2021.03. 31.437925 [PREPRINT]

McEwan WA, Hauler F, Williams CR, Bidgood SR, Mallery DL, Crowther RA, James LC (2012) Regulation of virus neutralization and the persistent fraction by TRIM21. J Virol 86: 8482-8491

Moss B (2011) Smallpox vaccines: targets of protective immunity. Immunol Reu 239: 8-26
Mukai Y, Yoshinaga T, Yoshikawa M, Matsuo K, Yoshikawa T, Matsuo K, Niki K, Yoshioka Y, Okada N, Nakagawa S (2011) Induction of endoplasmic reticulum-endosome fusion for antigen cross-presentation induced by poly (gamma-glutamic acid) nanoparticles. J Immunol 187: $6249-6255$

Nakanaga K, Yamanouchi K, Fujiwara K (1986) Protective effect of monoclonal antibodies on lethal mouse hepatitis virus infection in mice. $J$ Virol 59: 168-171

Papa G, Mallery DL, Albecka A, Welch LG, Cattin-Ortola J, Luptak J, Paul D, McMahon HT, Goodfellow IG, Carter A et al (2021) Furin cleavage of SARSCoV-2 Spike promotes but is not essential for infection and cell-cell fusion. PLoS Pathog 17: e1009246

Reis e Sousa C, Germain RN (1995) Major histocompatibility complex class I presentation of peptides derived from soluble exogenous antigen by a subset of cells engaged in phagocytosis. J Exp Med 182: 841-851

Richter K, Oxenius A (2013) Non-neutralizing antibodies protect from chronic LCMV infection independently of activating FcgammaR or complement. Eur J Immunol 43: 2349-2360

Rottier PJ, Spaan WJ, Horzinek MC, van der Zeijst BA (1981) Translation of three mouse hepatitis virus strain A59 subgenomic RNAs in Xenopus laevis oocytes. J Virol 38: 20-26

Rydyznski Moderbacher C, Ramirez SI, Dan JM, Grifoni A, Hastie KM, Weiskopf D, Belanger S, Abbott RK, Kim C, Choi J et al (2020) Antigen-specific adaptive immunity to SARS-CoV-2 in acute COVID-19 and associations with age and disease severity. Cell 183: 996-1012

Sambhara S, Kurichh A, Miranda R, Tumpey T, Rowe T, Renshaw M, Arpino R, Tamane A, Kandil A, James O et al (2001) Heterosubtypic immunity against human influenza $A$ viruses, including recently emerged avian $\mathrm{H} 5$ and $\mathrm{H} 9$ viruses, induced by FLU-ISCOM vaccine in mice requires both cytotoxic T-lymphocyte and macrophage function. Cell Immunol 211: $143-153$

Schmaljohn AL (2013) Protective antiviral antibodies that lack neutralizing activity: precedents and evolution of concepts. Curr HIV Res 11: 345-353

Sette A, Crotty S (2021) Adaptive immunity to SARS-CoV-2 and COVID-19. Cell 184: $861-880$

Straub T, Schweier O, Bruns M, Nimmerjahn F, Waisman A, Pircher H (2013) Nucleoprotein-specific nonneutralizing antibodies speed up LCMV elimination independently of complement and FcgammaR. Eur J Immunol 43: $2338-2348$

Wilson JA, Hevey M, Bakken R, Guest S, Bray M, Schmaljohn AL, Hart MK (2000) Epitopes involved in antibody-mediated protection from Ebola virus. Science 287: 1664-1666

Zeng J, Slodkowicz G, James LC (2019) Rare missense variants in the human cytosolic antibody receptor preserve antiviral function. Elife 8: e48339

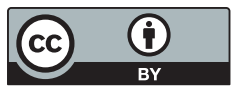

License: This is an open access article under the terms of the Creative Commons Attribution 4.0 License, which permits use, distribution and reproduction in any medium, provided the original work is properly cited. 